\title{
The Ideas of Basketball Teaching Reform in Colleges and Universities
}

\author{
Jianghong Li \\ Physical Education Department \\ Wuhan Huaxia University of Technology \\ Wuhan, P.R.China
}

\begin{abstract}
The essay mainly discusses the current situation of basketball teaching in university by literature, questionnaire and so on. At the same time, according to the understanding of the outline of ball course, the university basketball teaching will have the character of popularization and amusement, break the traditional teaching thoughts and methods and reform the teaching structure, teaching theory, teaching management and teaching evaluation. The students will be able to teach the basketball course and guide and develop the basketball sports.
\end{abstract}

Keywords—common college; basketball teaching; research

\section{INTRODUCTION}

Basketball is very popular in colleges and universities in our country. It is not only one of the main contents of sports teaching in colleges and universities, but it is also the most popular game among students' extracurricular physical exercises. As is shown in the questionnaire about college students' physical education learning self-consciousness and motivation in common colleges and universities, more than $75 \%$ of college students engage in basketball sport. It is the core issue of basketball teaching reform how to make the basketball teaching better adapt to the enforcement of the teaching thought like "quality education", "lifelong education" and so on, how to put into the teaching practice the educational functions and cultural connotations of basketball, to improve students' physical, psychological and social qualities, achieve the teaching aim of lifelong physical ability training. This paper puts forward some new ideas for basketball teaching reform.

\section{THE CURRENT STATE AND SHORTCOMINGS OF}

\section{BASKETBALL TEACHING IN COLLEGES AND UNIVERSITIES}

China's basic education curriculum design and compilation method, based on the former Soviet Union and western curriculum theory, is formed after long-term development. At present, it has formed its own set of fixed patterns, with greater inertia and stability. Basketball teachers are the carriers of knowledge and students are the receivers of knowledge. The subject and the center are teachers, and learning is a passive process, even a one-way output process. Basketball teachers know what is taught, while students are the object of a wait for processing, rather than the body of the free comprehensive development.
Basketball teaching is unable to provide the development of personality and inspire students' motivation of doing sports, which consequently can't make students form the habit of lifelong physical exercise.

The current college physical education teaching focuses on the meaning of "people" and the harmony between people and the society. It shows the humanities sports, health sports, lifelong sports, involving the lifelong need, independent ability and humanistic consciousness. It puts emphasis on quality education, health consciousness, the meaning of life, which involves the construction of the sports method, quality $\mathrm{PE}$, and lay more emphasis on sports nature, cultural value, the main consciousness, behavior ability in the educational process. So basketball course teaching in colleges and universities sports curriculum is to change the traditional teaching mode to adapt to the need of modern sport teaching reform, is to cultivate strong comprehensive quality of sports talents.

\section{THE IDEAS AND THOUGHTS OF COLLEGE BASKETBALL TEACHING REFORM}

\section{A. The Reform on the Basketball Teaching Thoughts is the First Reform of Basketball Teaching in Colleges and Universities}

With the establishment of the teaching concepts like "quality education", "lifelong education" and so on, the teaching concepts have developed from the past biological concepts into modern sports teaching views with the combination of biology, psychology and society. College basketball teaching reforming goal, therefore, should not only attach importance to the students' mastery of skills and improvement of qualities, but also put emphasis on the basic needs of students' psychological development, especially the cultivation of the students' self-exercise ability and sense of participation, in order to lay the foundation for the realization of the teaching goals of taking part in physical exercise for life. Traced back, basketball was the result of the game, at first in the form of simple matches, and then gradually was developed into influential competitive sports. For more than 100 years, the basic characteristics of basketball have never been out of the game.

The long-term traditional teaching of basketball has distorted the true nature of "popularization" and 
"entertainment" of school basketball. Ordinary university basketball education reform, first of all, should retreat from a single goal of skill teaching and establish a teaching environment aiming at the basketball game and entertaining match teaching, and create the teaching model with the characteristics of "popularization" and "entertaining" , using the process evaluation. On the basis of fully mobilizing students' learning initiative and enthusiasm, students' consciousness of basketball and the all-round development of comprehensive ability will be effectively promoted and the students' ability of self-evaluation and self-exercise ability will be raised and the exercise habit will be finally formed.

\section{B. Give Attention to the Synchronous Development of}

Students' Psychology and Physiology, Enrich the

Students' Cognition Structure and Experience System of

Basketball, and Promote the Transformation Process

from Knowledge to Ability

Comrade Mao Zedong had an incisive discussion in the study of sports: "if you want to achieve the effect of sports, you must not move it subjectively. Obviously, it is easy to see that the higher level of teaching needs and teaching effects cannot be realized without the improvement of students' subjective cognition. Modern teaching theory holds that any teaching process is a mixed information exchanging system with cognitive activities as the core. The active participation of students cannot realize the unimpeded information exchanging system of cognitive activities in the teaching process. Therefore, entertaining psychological induction, as a breakthrough point, can be gotten from students' participation in the basketball movement process. The basic needs of the development of students' physical and psychological synchronization can be met. Enriching the cognitive structure and experience system of students' participation in basketball sport and improving their active participation and demand level are the basis of realizing the basketball teaching reform.

\section{We Will Highlight the Organic Combination of}

Basketball Culture and Basketball Practice, Continue

Students' Habit of Learning, and Achieve the Teaching

Goal of Lifelong Participation in Basketball Sports

\section{Training}

The history of more than 100 years proves that basketball is a game, entertainment, competitive sports with rich cultural connotations and also an important part of the wealth of human civilization. Considered as a carrier of culture and educational function, basketball has become a form of education with the integration of recognition, cultivation and development. In the teaching, combining the basketball culture and practice is beneficial to improve students' macro understanding of basketball sports, understand educational culture, physical culture, mind-keeping culture and entertainment culture contained in basketball, and enhance students' basketball awareness, rich emotions, moral respect for basketball, the pursuit of basketball value and basketball mind. Teachers should continue the students' perception of basketball theory and practice and raise students' ability of life-long participation into basketball sports.

\section{Teachers Should Give a Full Pay to Educational} Functions of Basketball, Pay Attention to Students' Outlook on Life, Values, Physical and Mental Health and Other Internal Conditions, so as to Obtain the Unity of Learning Ability Growth and Personality Growth

The ultimate goal of physical education is to achieve the growth of students' personality. In basketball teaching, teachers should introduce rich teaching contents, and in the time of the growth of basketball professional qualification, make the students feel the infinite power of the personality growth brought by basketball culture and education. As a matter of fact, the basketball sport is actually a game in which those who make less mistakes will win the game, and therefore, the basketball education process is a process of correcting mistakes. In this process, the teaching activities should regard training students to develop "habit" as a center for the teaching. At the same time, through basketball knowledge learning, skill training, quality cultivation and cultural edification, students can be clear about which thoughts and behaviors are correct in basketball practice, what is wrong, and grasp the standard of judging right and wrong.

\section{E. The Main Goal of Basketball Course Is to Cultivate the Spirit of Unity and Cooperation, Teamwork, Courage and Tenacity, and the Quality of Wit and Determination}

In order to train talented people with high professional quality, colleges and universities can give full play to their professional characteristics after graduation and meet the needs of social development. Therefore, college students should strengthen physical exercise in school, master one or two scientific physical exercise methods, and finally achieve the goal of health and entertainment, and enhance physical fitness. Basketball has its unique charm. Through learning and playing, it can cultivate people's solidarity and cooperation, team spirit of cooperation, courage and tenacity, wit and determination. Also, basketball group activities can strengthen contacts and exchanges between students of the time, can let students forget a day of trouble and pain, eliminate the tight learning atmosphere and the loneliness, and gradually form consciousness and habit of communication.

In the course of basketball activities, the feelings between students will be transferred to daily life, study and work to promote people's social communication ability. As a team sport, basketball cooperation is not only a necessary quality for basketball players, but also an ability developed through basketball courses, training and competitions. For example, if two people want to succeed in getting shots in the basketball matches, they must get their companions' help and cooperation and strengthen the defense, only through close cooperation with team mates. Therefore, in the collective sport of basketball, we must cooperate with our partners to achieve the collective goal and give full play to our individual role. 
Basketball helps form a sense of competition. The competition in modern society is becoming more and fiercer. It is helpful for college students to adapt to the society after they leave school. One of the main characteristics of basketball is strong competition and antagonism, and it develops in a fast changing situation. Not only does it challenge their own sports ability, but it also challenges the competition with others; there is a competition between individuals and groups. And in the competition, college students must win the game by their own ability to overcome the other side. Therefore, basketball teaching should arrange more games on the basis of certain skills to cultivate students' collective spirit of unity, cooperation and cooperation, as well as the qualities of bravery, tenacity and wit and determination.

\section{CONCLUSION}

Throughout the reform of college sports, basketball teaching regards "popularization" and "entertaining" as the teaching characteristics, meets the students' basic psychological and physiological needs and give full play to the most basic functions of basketball, establish and perfect the teaching environment aiming at basketball games, entertainment and game teaching, and create a teaching mode characterized "popularization" and "entertainment". The main body of learning initiative and enthusiasm gives full play to the rich cultural connotations of basketball teaching, improves skills, emphasizes the awareness, attitude and the cultivation of team spirit, promote the allround development of basketball, finally realizes the students' exercise ability, and the exercise habit.

\section{REFERENCES}

[1] Xu Yuanjun, Qiu Jianguo. The New Direction of PE Reform Plan[J]. PE \& Science,2016,23(5).

[2] SunMinzhi. The Advanced Course of Basketball Sport [ M] .People's Publishing House, 2014,(2).

[3] Yang Hua. The Teaching Reform and Development of PE Colleges[J] .Journal of Chengdu Sport University, 2015, (3) .

[4] lu Xiaohui. Some Thoughts on Basketball Teaching Reform in Sports Colleges and Universities[ J] .Journal of Jilin University of Sports, 2017, (4) .

[5] Cao Jingcheng. Analysis and Attempts of College Basketball Reform[ J] .PE \& Science, 2012, 23 (5). 